\title{
Effect of increasing the proportion of dietary concentrate on gastrointestinal tract measurements and brush border enzyme activity in Holstein steers
}

\author{
P. Górka, ${ }^{* 1}$ B. L. Schurmann,† M. E. Walpole,† A. Błońska, ${ }^{*}$ S. Li,ł J. C. Plaizier,ł Z. M. Kowalski, ${ }^{*}$ \\ and G. B. Pennert ${ }^{1}$ \\ *Department of Animal Nutrition and Dietetics, University of Agriculture in Krakow, Al. Mickiewicza 24/28, 30-059 Krakow, Poland \\ †Department of Animal and Poultry Science, University of Saskatchewan, 51 Campus Dr, Saskatoon, Saskatchewan, S7N 5A8, Canada \\ fUniversity of Manitoba, Winnipeg, R3R 3N2, Canada
}

\section{ABSTRACT}

The aim of this study was to determine the time course for adaptation of the reticulo-rumen, omasum, abomasum, and small intestine in response to an abrupt increase in the proportion of grain in the diet. Adaptive responses include tissue and digesta mass, small intestinal length, and brush border enzyme activity in the duodenum, proximal jejunum, and ileum. Twentyfive Holstein steers $(213 \pm 23 \mathrm{~kg} ; 5$ to 7 mo of age) were blocked by body weight, and within block were randomly assigned to 1 of 5 treatments: the control diet (CTRL; 92\% chopped grass hay and $8 \%$ mineral and vitamin supplement on a dry matter basis) or a moderate grain diet (MGD; 50\% chopped grass hay, $42 \%$ rolled barley grain, and $8 \%$ mineral and vitamin supplement) that was fed for 3 (MGD3), 7 (MGD7), 14 (MGD14), or $21 \mathrm{~d}$ (MGD21). Dry matter intake was limited to $2.25 \%$ of body weight to ensure that changes in dry matter intake did not confound the results. On the last day of the dietary exposure, steers were slaughtered $2 \mathrm{~h}$ after feeding. Reticulo-rumen tissue mass and ruminal epithelium mass in the ventral sac of the rumen were not affected by the MGD. Wet reticuloruminal digesta mass decreased from CTRL to MGD7 and then increased, but reticulo-ruminal digesta dry matter mass did not differ between treatments. Omasal mass, omasal tissue mass, and omasum digesta mass decreased linearly with the number of days fed MGD, but abomasal tissue mass tended to increase linearly. Duodenal tissue mass tended to increase linearly, and ileal length increased linearly with the number of days fed MGD. Lactase activity in the proximal jejunum increased linearly and maltase activity in duodenum tended to increase linearly with days fed MGD. Amino-

\footnotetext{
Received October 16, 2016.

Accepted February 3, 2017.

${ }^{1}$ Corresponding authors: p.gorka@ur.krakow.pl and greg.penner@
} usask.ca peptidase $\mathrm{N}$ activity in the proximal jejunum increased cubically with days fed MGD, and dipeptidylpeptidase IV activity in ileum tended to decrease from CTRL to MGD14 and then tended to increase. Adaptation to a diet with a greater proportion of concentrate involves changes in the mass and length of regions of the gastrointestinal tract and brush border enzyme activity. These changes take place gradually over at least 3 wk. Key words: starch, adaptation, forestomach, intestine

\section{INTRODUCTION}

To increase dietary energy density, diets for highyielding dairy cows and growing and finishing beef cattle commonly include substantial quantities of grain (Steele et al., 2011; Schwaiger et al., 2013). Although this feeding strategy is necessary to achieve high levels of production, feeding highly fermentable diets poses a challenge for the gastrointestinal tract (GIT) epithelium in ruminants (Steele et al., 2011; Liu et al., 2013; Metzler-Zebeli et al., 2013). Consumption of highly fermentable carbohydrates increases the rate of shortchain fatty acid (SCFA) production in the rumen, which may lead to SCFA accumulation in the rumen and a reduction in ruminal $\mathrm{pH}$ (Aschenbach et al., 2011). Additionally, diets with moderate to high grain content may increase lactic acid production in the rumen and reduce saliva secretion, further reducing ruminal $\mathrm{pH}$ (Liu et al., 2013; Chibisa et al., 2016). This situation, commonly referred as subacute rumen acidosis, may lead to less efficient fiber digestion (Calsamiglia et al., 2002; Zebeli et al., 2008), reduced GIT barrier function (Wilson et al., 2012; Liu et al., 2013), translocation of pathogens and endotoxins into the systemic circulation (Plaizier et al., 2008; Li et al., 2012), and liver abscesses (Nagaraja and Titgemeyer, 2007; Plaizier et al., 2008). Furthermore, as the proportion of grain in the diet increases, the amount of starch entering and fermented in the hindgut also increases (Harmon, 2009; Brake et al., 2014). Increased hindgut fermentation can lead to a reduction in large intestinal $\mathrm{pH}$, an increase in endotoxin 
concentration in the digesta, and a corresponding reduction in the expression of tight-cell junction proteins (Li et al., 2012; Metzler-Zebeli et al., 2013).

Cattle should be gradually adapted to diets that are more fermentable (Steele et al., 2011; Schwaiger et al., 2013). Reasons for this include the fact that microbial adaptation and morphological adaptation of the ruminal epithelium require 3 to 9 wk (Dirksen et al., 1985; Tajima et al., 2001; Bannink et al., 2008), and that functional adaptation, although much faster, proceeds over at least 3 wk after a dietary change (Etschmann et al., 2009; Schurmann et al., 2014; Walpole et al., 2015). Although it has been rarely investigated, small and large intestinal tissue mass increases in the first week of lactation, a period associated with an increase in concentrate intake (Reynolds et al., 2004). Therefore, adaptation of the lower regions of the GIT may also require time. However, under practical conditions, cattle often receive substantial increases in rapidly fermentable carbohydrates over a relatively short period. Examples of scenarios in which such rapid dietary change occurs include transition from the dry period to lactation, weaning, arrival at a feedlot, and adaptation to a finishing diet.

The GIT of cattle adapts to an increased proportion of grain in the diet at both morphological and cellular (functional) levels. Increased consumption and the subsequent fermentation of rapidly fermentable carbohydrate results in greater proliferation of ruminal epithelial cells, greater ruminal papillae dimensions, and, in consequence, greater surface area for SCFA absorption (Goodlad, 1981; Bannink et al., 2008; Malhi et al., 2013). The increased surface area of the ruminal epithelium also translates to greater reticulo-ruminal tissue mass (Stobo et al., 1966; Reynolds et al., 2004; Malhi et al., 2013). Furthermore, concentrate intake increases the permeability of ruminal epithelium to SCFA (Amat et al., 2014) by increasing passive and anion exchange pathways for SCFA absorption (Schurmann et al., 2014). Moderate to high grain intake has also been associated with greater abomasal and small intestinal tissue mass (Stobo et al., 1966; Reynolds et al., 2004), indicating a greater importance of those regions of the GIT when the plane of nutrition increases. Additionally, supplementation with concentrate has been reported to increase mRNA expression of sugar transporters in the small intestinal epithelium (Li et al., 2016), and increased provision of concentrate (and its associated greater energy intake) increases brush border enzyme activity (Kreikemeier et al., 1990). On the other hand, lower omasal tissue mass has been observed when the proportion of forage in the diet decreased (Hamada et al., 1976; Bailey, 1986; McLeod and Baldwin, 2000). As a result, adaptation of not only the reticulo-rumen but also the omasum, abomasum, and intestine may be important in determining the efficiency of dietary nutrient use, especially when grain intake is rapidly increased.

An abrupt increase in fermentable carbohydrate intake may have a detrimental effect on ruminal function, because it leads to a reduction in $\mathrm{pH}$, damage of the ruminal epithelium, and less efficient SCFA absorption (Krehbiel et al., 1995; Steele et al., 2011; Schwaiger et al., 2013). At least several days are needed for the ruminal epithelium to recover after bout of ruminal acidosis (Steele et al., 2011; Schwaiger et al., 2013), but less efficient SCFA absorption may be observed for up to the next 3 mo (Krehbiel et al., 1995). This may delay adaptation of the reticulo-rumen (Schwaiger et al., 2013) and other regions of the GIT to dietary change. However, so far, only a limited number of studies have evaluated the time course of changes in the structure and function of the GIT in cattle in response to dietary change (Reynolds et al., 2004; Etschmann et al., 2009; Steele et al., 2011). Knowledge of how the GIT adapts to increased dietary fermentability may increase our knowledge of factors that limit the efficiency of nutrient use in intensively fed cattle.

We hypothesized that the tissue mass of the reticulorumen, abomasum, and small intestine, small intestinal length, and brush border enzyme activity would increase and omasal tissue mass would decrease in response to an abrupt exposure to a diet containing a higher proportion of grain. We further hypothesized that those changes would progress gradually over at least $21 \mathrm{~d}$. The aim of this study was to determine the time course for adaptation of the reticulo-ruminal, omasal, and abomasal tissue mass, small intestinal mass and length, and intestinal brush border enzyme activity in response to an abrupt increase in the proportion of grain in the diet. We also investigated the time course of adaptation for the reticulo-ruminal, omasal, and abomasal digesta mass.

\section{MATERIALS AND METHODS}

The steers used for this study were cared for in accordance with the Canadian Council for Animal Care guidelines, and all experimental procedures were preapproved by the University of Saskatchewan Animal Research Ethics Board (protocol 20100021).

\section{Steers and Experimental Diets}

Steers used for this study and the experimental procedures have been described elsewhere (Plaizier et al., 2014; Schurmann et al., 2014; Walpole et al., 2015). Briefly, 25 Holstein steers $(213 \pm 23 \mathrm{~kg} ; 5$ to 7 mo of age) fed a common high-forage diet (92\% grass hay, 
$8 \%$ barley-grain-based vitamin and mineral supplement, on a DM basis) for at least 5 wk were blocked by BW and randomly assigned to 1 of 5 treatments: the control diet (CTRL; 92\% chopped grass hay and $8 \%$ mineral and vitamin supplement with barley grain used as a carrier; DM basis) or a moderate grain diet (MGD; 50\% chopped grass hay, 42\% rolled barley grain, and $8 \%$ mineral and vitamin supplement) that was fed for 3 (MGD3), 7 (MGD7), 14 (MGD14), or $21 \mathrm{~d}$ (MGD21). Diets were fed at $2.25 \%$ of BW once per day $(0800 \mathrm{~h})$ and were formulated to meet nutrient requirements to achieve a growth rate of at least 0.5 $\mathrm{kg} / \mathrm{d}$ (NRC, 2000). Because diets differed in forageto-concentrate ratio but DMI was held constant, diets were not isoenergetic. Steers were kept in individual pens $\left(12.2 \mathrm{~m}^{2}\right)$ with floors covered with rubber mats for at least $14 \mathrm{~d}$ before slaughter. Once in the individual pens, steers' feed intake was limited. Feed intake was recorded daily (with the exception of the day of slaughter), and water was available ad libitum throughout the study period.

\section{Measurements and Sample Collection}

On the last day of dietary exposure, steers were slaughtered $2 \mathrm{~h}$ after feeding by captive bolt stunning followed by pithing and exsanguination. The entire forestomach, abomasum, and small intestine were dissected. The reticulo-ruminal contents were removed, reticulo-ruminal tissue and digesta were weighed, and 2 representative samples of the reticulo-ruminal digesta $\left(1 \mathrm{~kg}\right.$ each) were collected and kept frozen $\left(-20^{\circ} \mathrm{C}\right)$ for analysis. The omasal and abomasal regions were weighed full and after removal of the digesta. To facilitate the empty weight measurement, each stomach compartment was rinsed repeatedly with water, water was pressed by hand and shaken down 2 times, and then each compartment was weighed individually. Then, 2 pieces of whole tissue $(5 \times 5 \mathrm{~cm})$ from the ventral sac of the rumen were collected and kept frozen $\left(-20^{\circ} \mathrm{C}\right)$ for analysis. The small intestine was divided into the duodenum (with the end determined by the ligament of Treitz), jejunum (with the end determined based on the ileocecal fold), and ileum (with the end at the ileocecal junction). Small intestinal tissues were carefully separated from the intestinal mesentery, emptied, measured, and weighed individually. Epithelial samples from the midpoint of the duodenum, the proximal jejunum ( $2 \mathrm{~m}$ from the end of duodenum), and the midpoint of the ileum were scraped using a microscope slide. The samples were then frozen in liquid nitrogen and stored at $-80^{\circ} \mathrm{C}$. Ruminal tissue was completely thawed, and the epithelium was manually stripped from the muscle layers. Both epithelium and muscle layers were dried in a forced-air oven at $105^{\circ} \mathrm{C}$ until they achieved a constant weight to determine epithelium and muscle DM. Reticulo-ruminal digesta samples were dried in a forced-air oven $\left(\right.$ at $55^{\circ} \mathrm{C}$ until they achieved a constant weight) to determine digesta DM concentration and reticulo-ruminal DM content. Reticulo-ruminal DM and moisture content were calculated as follows: reticulo-ruminal DM content $(\mathrm{kg})=$ reticulo-ruminal digesta content $(\mathrm{kg}) \times$ reticulo-ruminal digesta DM concentration (\%)/100 (\%) and reticuloruminal moisture content $(\mathrm{kg})=$ reticulo-rumen digesta $(\mathrm{kg})$ - reticulo-ruminal digesta DM content $(\mathrm{kg})$.

\section{Brush Border Enzyme Activity}

The total protein content and activity of selected brush border enzymes in the intestinal epithelial scrapings were determined as described previously (Górka et al., 2011). Briefly, $1 \mathrm{~g}$ of epithelial scrapings was homogenized with $5 \mathrm{~mL}$ of distilled water and centrifuged for 5 min at $1,000 \times g$ at $4^{\circ} \mathrm{C}$ to obtain a supernatant. The supernatant was used to determine the total protein and brush border enzyme activity. The total protein content was determined according to Hartree (1972) using bovine serum albumin as a standard. Lactase and maltase activities were determined according to Dahlqvist (1984) with minor modifications (Górka et al., 2011). Aminopeptidase A, aminopeptidase N, and dipeptidylpeptidase IV activity were determined using L-glutamyl- $p$-nitroanilide, L-leucyl- $p$-nitroanilide, and L-glycyl- $p$-nitroanilide (Bachem, Budendorf, Sweden) as substrates, respectively (Maroux et al., 1973; Nagatsu et al., 1976). Each sample was run in duplicate. Analysis of each enzyme was conducted in a temperaturecontrolled laboratory using 1 set of reagents and was completed on consecutive days until all samples were analyzed. The intraassay CV were $1.77 \pm 1.08,1.83 \pm$ $1.43,2.17 \pm 1.75,6.86 \pm 3.38,6.31 \pm 3.01$, and 6.85 \pm 3.12 for total protein, maltase, lactase, aminopeptidase $\mathrm{N}$, aminopeptidase $\mathrm{A}$, and dipeptidylpeptidase IV analysis, respectively. Enzymatic activity was presented as enzymatic units normalized for total protein content in the supernatant $\left(\mathrm{U} \times 10^{-3} / \mathrm{mg}\right.$ of protein), with 1 enzymatic unit expressing $1 \mu \mathrm{mol}$ of glucose or $p$-nitroanilide released $/ \mathrm{min}$ of reaction at $37^{\circ} \mathrm{C}$.

\section{Statistical Analysis}

Data were analyzed as a randomized block design using the MIXED procedure of SAS (version 9.2; SAS Institute Inc., Cary, NC). The statistical model included the fixed effect of treatment and the random effect of block and can be described as follows: 


$$
Y_{i j}=\mu+\rho_{i}+\alpha_{j}+e_{i j}
$$

where $Y_{i j}=$ an observation value for GIT measurements and brush border enzyme activities taken from block $i$ and treatment $j ; \mu=$ overall mean for the population; $\rho_{i}=$ random effect of block $i$, where $i=$ block $1,2,3,4$, or $5 ; \alpha_{j}=$ fixed effect of treatment $j$, where $j=$ CTRL, MGD3, MGD7, MGD14, or MGD21; and $e_{i j}=$ error term specific for the steer assigned to $j$ th treatment in the $i$ th block.

The hypotheses were tested using preplanned orthogonal (CTRL vs. MGD) and polynomial contrasts (linear, quadratic, and cubic effects) accounting for unequal spacing in the duration of time steers were fed the MGD. Polynomial contrasts included the CTRL treatment. Significance was declared when $P \leq 0.05$, and tendencies were discussed when $0.10 \leq P>0.05$.

\section{RESULTS}

Data on BW, DMI, and reticulo-ruminal fermentation have been presented in a companion paper (Schurmann et al., 2014). Briefly, BW and DMI were not different between treatments $(P \geq 0.47)$. We observed almost no refusals, but feed intake on the last day of study (slaughter day) was not recorded. Minimum, mean, and maximum reticular $\mathrm{pH}$ decreased from 6.57, 6.90, and 7.22 for CTRL to 6.08, 6.59, and 7.05 for MGD7 and increased thereafter to $6.31,6.79$, and 7.19 for MGD21 (quadratic, $P \leq 0.01$ ). Total SCFA $2 \mathrm{~h}$ after feeding (slaughter point) was not different between treatments $(P \geq 0.25)$. However, the molar proportion of acetate decreased cubically from $67.8 \%$ for CTRL to $63.6 \%$ for MGD7, followed by an increase to $64.0 \%$ for MGD14 and MGD21 (quadratic, $P<0.01$ ). The molar proportion of butyrate increased from $9.6 \%$ for CTRL to $13.0 \%$ for MGD14 and then decreased to $11.9 \%$ for MGD21 (quadratic, $P<0.01$ ). The molar proportion of propionate was not affected by days fed MGD.

Reticulo-ruminal tissue mass was not affected by MGD ( $P \geq 0.33$; Table 1). However, reticulo-ruminal digesta wet mass decreased from CTRL to MGD7 and then increased (quadratic, $P=0.03$ ), and reticuloruminal digesta DM content increased linearly with number of days fed MGD $(P<0.01)$. Reticulo-ruminal digesta DM mass did not differ between treatments, but digesta moisture mass decreased from CTRL to MGD7 and then increased (quadratic, $P=0.02$ ).

Omasal mass, omasal tissue mass, and omasal digesta mass decreased $(P \leq 0.02)$, but abomasal tissue mass tended to $(P=0.07)$ increase linearly with number of days fed MGD. Duodenal tissue mass tended to $(P$ $=0.06)$ increase linearly, and ileal length increased $(P$ $=0.02$ ) linearly with number of days fed MGD. We detected no effect on other measurements of the abomasum and small intestine.

The dry mass of the epithelium from the ventral sac of rumen was not affected by MGD, but the dry mass of the muscle increased from CTRL to MGD14 and then decreased (quadratic, $P=0.02$; Table 2). As a result, the ratio of epithelial dry mass to muscle dry mass decreased from CTRL to MGD14 and then increased (quadratic, $P=0.01$ ). Epithelial DM content increased linearly $(P=0.03)$ with number of days fed MGD, but muscle DM content increased from CTRL to MGD7 and then decreased (quadratic, $P=0.03$ ).

Lactase activity in the proximal jejunum increased $(P=0.02$; Table 3$)$ linearly, and maltase activity in the duodenum tended to increase $(P=0.08)$ linearly with days fed MGD. Furthermore, maltase activity in the proximal jejunum tended to be greater for MGD than for CTRL $(P=0.09)$. Aminopeptidase $\mathrm{N}$ activity in the proximal jejunum increased $(P=0.01)$ cubically with days fed MGD and tended to $(P=0.09)$ be greater for MGD than for CTRL. Dipeptidylpeptidase IV activity in ileum tended to decrease from CTRL to MGD14 and then tended to increase (quadratic, $P=0.07$ ).

\section{DISCUSSION}

Previous studies have suggested that several weeks are needed for the ruminant GIT to adapt to diets with greater fermentability, mainly because several weeks are needed for ruminal microflora adaptation (Tajima et al., 2001; Fernando et al., 2010) and enlargement of the surface area of the ruminal epithelium to promote nutrient absorption (Dirksen et al., 1985; Bannink et al., 2008; Dieho et al., 2016). Furthermore, the tissue mass of the omasum, abomasum, and small intestine (Stobo et al., 1966; Reynolds et al., 2004), secretion of digestive enzymes (Kreikemeier et al., 1990), and expression of genes encoding nutrient transporters (Liu et al., 2013; Metzler-Zebeli et al., 2013) are also affected by dietary factors and may also require time to adopt to dietary changes. However, in commercial settings, cattle often experience abrupt increases in fermentable carbohydrate intake. Therefore, although the rate of adaptation is important, understanding the transient responses associated with adaptation of the GIT is also necessary, because it relates to the efficiency of nutrient use and the health of cattle on these diets. In this study, we investigated changes in GIT tissue mass and length, digesta mass, and brush border enzyme activity over a 21-d adaptation period following an abrupt increase in the proportion of grain in the diet. Results describing the effects of treatments used in this study on SCFA absorption (Schurmann et al., 2014), urea flux across the ruminal epithelium (Walpole et al., 2015), and en- 


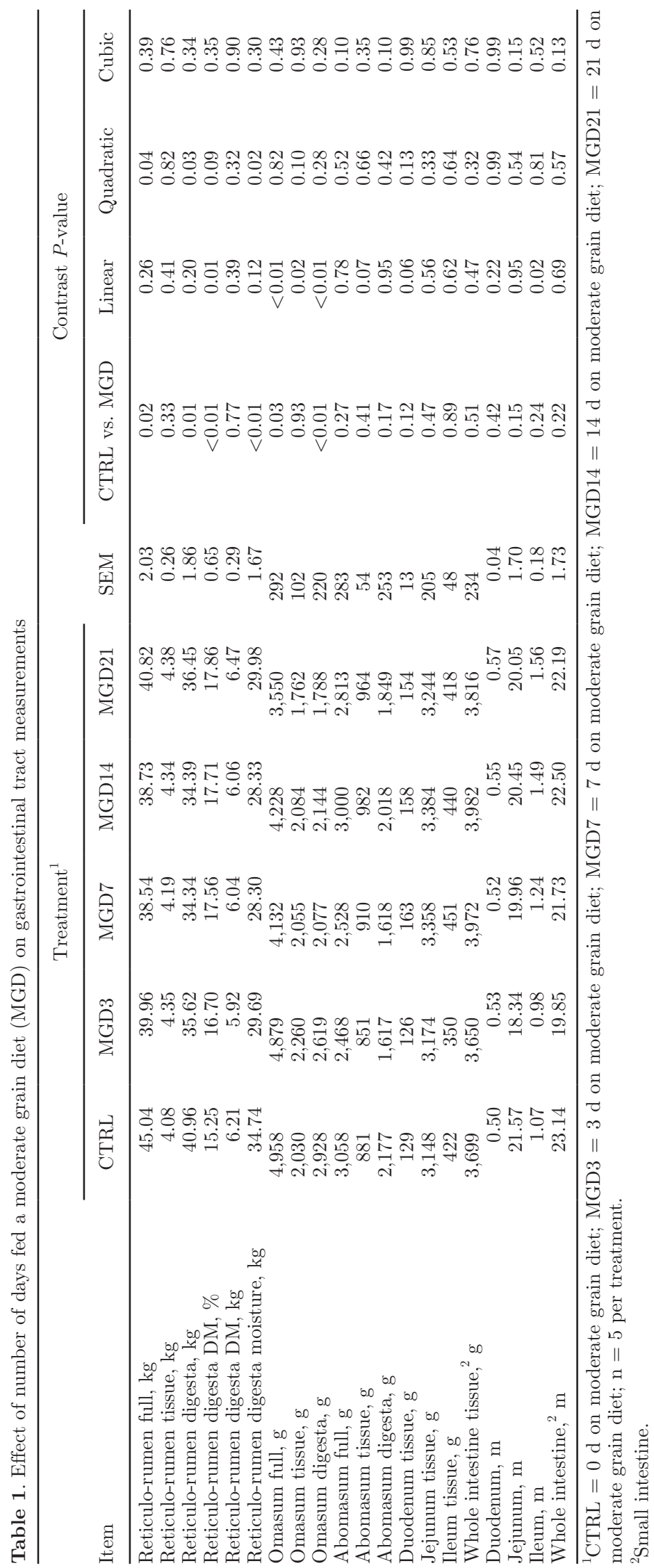




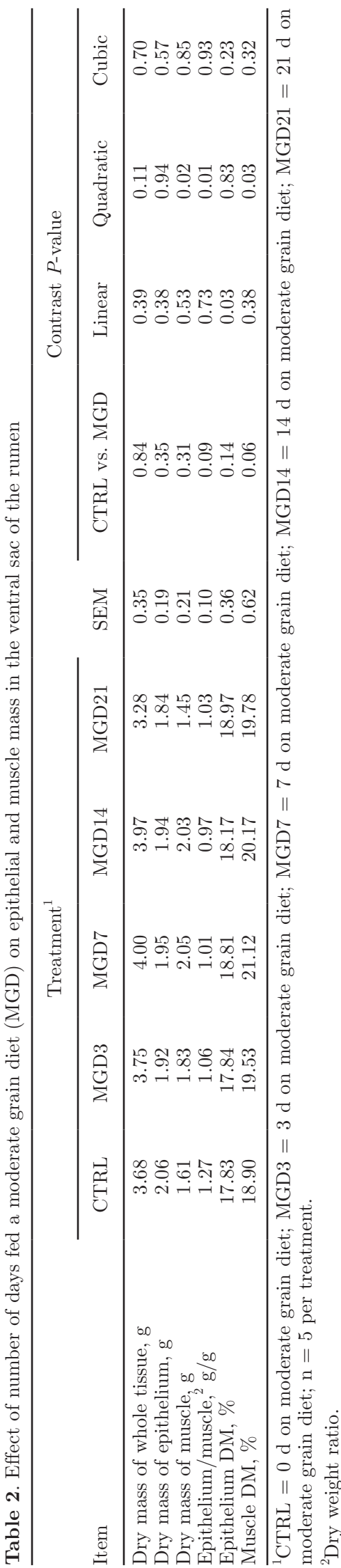

dotoxin concentration in regions of the GIT (Plaizier et al., 2014) have been reported in companion papers. Briefly, the results of those studies showed that sodium flux, mucosal-to-serosal acetate and butyrate flux, and serosal-to-mucosal urea flux across rumen epithelium increased with the number of days fed MGD (Schurmann et al., 2014; Walpole et al., 2015). Those functional changes preceded structural adaptation of the ruminal epithelium (e.g., enlargement of rumen papillae), indicating that functional adaptation occurs before tissue growth and associated enlargement of surface area for nutrient absorption. Furthermore, MGD increased LPS concentration in the digesta of reticulo-rumen, ileum, cecum, and colon (Plaizier et al., 2014). Taking into account the fact that LPS may directly compromise epithelial barrier function (Chin et al., 2006; Liu et al., 2013), regions more distal than the reticulo-rumen can be challenged with an abrupt increase in the proportion of grain in the diet (Plaizier et al., 2014).

In commercial conditions, rapid increases in grain intake take place during transition from the dry period to lactation and at weaning or on entering a feedlot. In most cases, the increase in concentrate intake is a result of increased proportion of grain in the diet and feed intake. To partially separate the effect of DMI and the proportion of grain in the diet, we restricted DMI in this study. Although a constant DMI was not fully representative of commercial settings, it did allow us to determine the adaptive response independent of changes induced by DMI.

\section{Adaptation of the Reticulo-Rumen}

Because moderate increases in the fermentable carbohydrate content of diets stimulate ruminal papillae growth (Dirksen et al., 1985; Bannink et al., 2008; Dieho et al., 2016) and result in greater rumen epithelial mass (Reynolds et al., 2004; Malhi et al., 2013), we expected that the reticulo-ruminal tissue mass would increase as adaptation of the ruminal epithelium to the MGD progressed. However, we detected no effects of the MGD for papillae dimensions and density (Schurmann et al., 2014) or for the weight of the ruminal epithelium from the ventral sac. This lack of response was most likely due to the timeline required for ruminal epithelial proliferation, and because epithelial growth and muscle mass may occur divergently. For example, past studies have suggested that approximately 3 to 9 wk are required for ruminal papillae to adapt to diets with a moderate level of fermentable carbohydrates (Dirksen et al., 1985; Bannink et al., 2008; Dieho et al., 2016). That said, these studies evaluated adaptation in response to dietary change coupled with increased DMI in the postpartum phase of the transition period for 
DIET AND GASTROINTESTINAL TRACT ADAPTATION

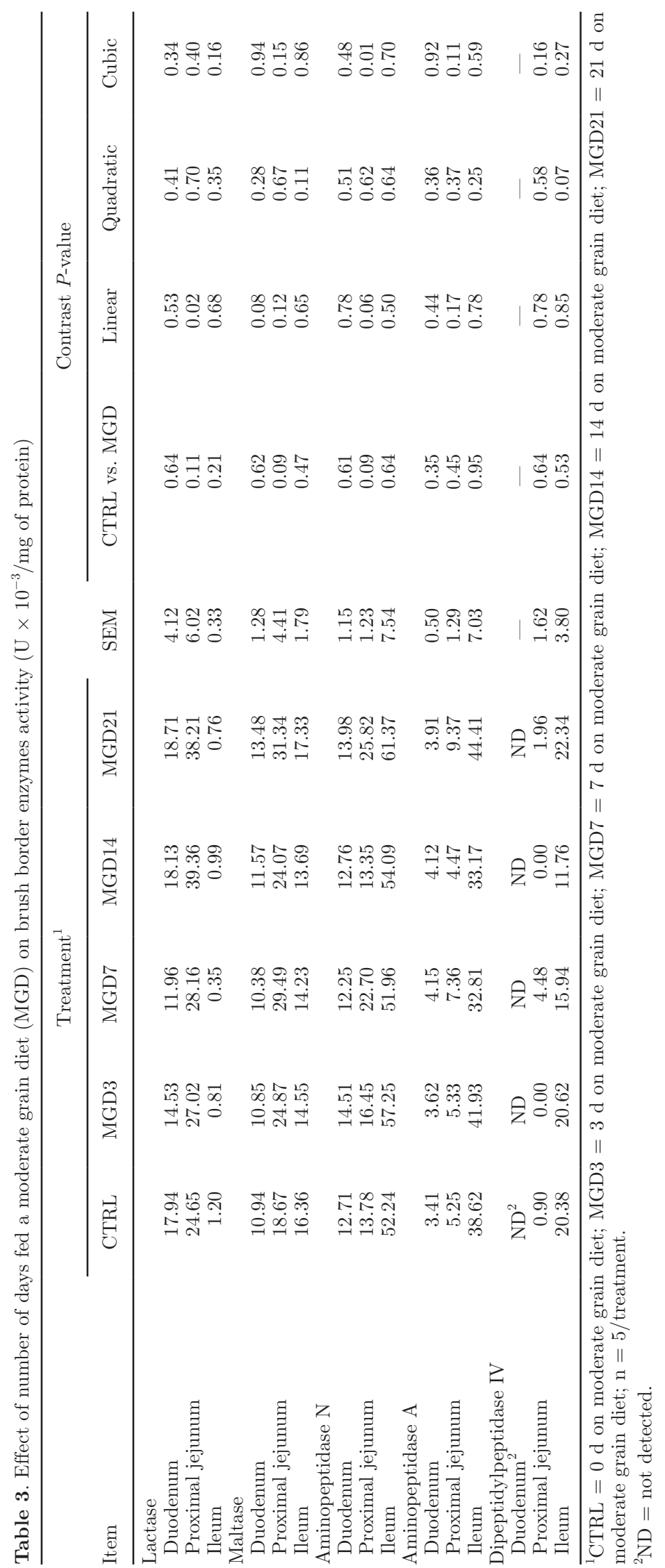


Holstein cows. Combined with the results of previous studies, our findings suggest that without a corresponding increase in DMI, increasing the fermentability of the diet has little effect on stimulating papillae proliferation (Schurmann et al., 2014) and ruminal epithelial tissue mass. We cannot exclude the possibility that the duration of our study was too short to detect changes in papillae morphology and ruminal tissue mass. However, when feed intake was limited, as in the present study, ruminal papillae length and width did not change, even after $6 \mathrm{wk}$ of exposure to a moderate- or high-grain diet (30 to 60\% in DM; Metzler-Zebeli et al., 2013). That said, increased absorption of sodium (Etschmann et al., 2009; Schurmann et al., 2014), acetate and butyrate uptake (Schurmann et al., 2014), and urea secretion (Walpole et al., 2015) occurred within $1 \mathrm{wk}$ following an abrupt dietary change. Others have also reported increased expression of genes encoding for proteins involved in SCFA absorption and intracellular $\mathrm{pH}$ regulation as an acute response to greater dietary fermentability (Metzler-Zebeli et al., 2013). These studies and the results from the present study suggest that changes in cellular activity occur acutely and may be prioritized over tissue growth, at least for short-term adaptation (Etschmann et al., 2009). Tissue growth and the associated enlargement of the surface area for nutrient absorption can be justified predominantly when functional adaptation is insufficient to ensure efficient nutrient absorption and when increased dietary fermentability and possibly DMI are sustained.

Another explanation for the lack of differences in reticulo-ruminal tissue mass is that it can be affected by the tissue mass of both the rumen and the reticulum. The tissue mass of the reticulum decreases with high-grain diets (McLeod and Baldwin, 2000), and a similar decrease after the abrupt change from CTRL to MGD could have contributed to a lack of difference in reticulo-ruminal tissue mass between the CTRL and MGD steers in this study. Unfortunately, we did not measure the tissue mass of the reticulum and rumen separately.

Because reticulo-ruminal tissue mass may be affected not only by epithelial mass but also by muscle mass (Harrison et al., 1960; Hamada et al., 1976), we measured epithelial and muscle mass in the ventral sac of the rumen. However, we observed the lowest muscle DM mass for CTRL and MGD21 and also MGD3, and these treatments corresponded with the heaviest digesta wet mass. Thus, muscle DM mass was most likely affected by tissue (muscle) stretching. This is plausible considering that we collected tissue samples $2 \mathrm{~h}$ after feeding. Observed differences in muscle DM mass between treatments in the present study should be interpreted with caution.
Previous studies have reported higher reticulo-ruminal DM content and lower reticulo-ruminal moisture content, longer DM retention time in the rumen, and lower fluid flow in ruminants fed moderate- to high-grain diets compared with those fed mostly forage (Colucci et al., 1990; Jaakkola and Huhtanen, 1993; Chibisa et al., 2016). Longer digesta retention time in the rumen, particularly fiber retention time, allows for partial compensation of reduced structural carbohydrate digestion when diets contain moderate to high grain inclusion, at least when feed intake is restricted (Colucci et al., 1990; Jaakkola and Huhtanen, 1993). Although we did not record DMI before slaughter in the present study, DMI among days was constant, so results on the day of slaughter should represent a reasonable estimate of the adaptive response over time. Nevertheless, our sampling approach allowed for only a single sampling time point. Therefore, precise interpretation of changes for reticulo-ruminal digesta mass with advancing days fed MGD could not be provided. That said, reticuloruminal DM mass was not affected, but reticulo-ruminal moisture mass decreased after the shift to MGD. Furthermore, after an initial decrease, reticulo-ruminal moisture mass increased from d 14 to 21 after the shift to MGD (quadratic pattern of change). This resembled the pattern of change for reticulo-ruminal $\mathrm{pH}$ observed in the present study (Schurmann et al., 2014). Diets with a moderate to high grain inclusion rate decrease liquid outflow from the rumen (Colucci et al., 1990; Jaakkola and Huhtanen, 1993; Chibisa et al., 2016). As a result, the lower reticulo-ruminal moisture mass in MGD steers may indicate lower fluid inflow, because of reduced saliva secretion or water intake. Saliva secretion decreases when the proportion of grain in the diet increases (Maekawa et al., 2002; Chibisa et al., 2016). Additionally, cattle transitioned to high-grain diet gradually alter their diet selection and sort for longer dietary particles (DeVries et al., 2014), which should increase chewing activity (Zebeli et al., 2008) and thus saliva secretion. It is thought that this altered sorting behavior is a compensatory mechanism to help regulate ruminal $\mathrm{pH}$ with high-grain diets. Although not measured in this study, the observed changes in reticuloruminal digesta mass may be attributed to changes in saliva secretion during the adaptation period and may help to explain observed changes in reticulo-ruminal pH (Schurmann et al., 2014), due to the known importance of saliva secretion for ruminal $\mathrm{pH}$ stabilization (Aschenbach et al., 2011; Chibisa et al., 2016). However, changes in water intake after the abrupt change to MGD and its effect on reticulo-ruminal digesta moisture mass cannot be excluded.

Combined, the results of this study confirm that adaptation of the rumen of cattle in response to an abrupt 
dietary change (without a change in DMI) is limited, as indicated by a transient decrease in reticulo-ruminal pH (Schurmann et al., 2014) and reticulo-ruminal digesta mass shortly after the dietary change, followed by a gradual increase with advancing days. Nevertheless, adaptation of the reticulo-ruminal tissue mass may be of little importance when feed intake is limited or the duration of exposure is short. Furthermore, the results of this and accompanying studies (Schurmann et al., 2014; Walpole et al., 2015) indicate that ruminal adaptation proceeded throughout the study period. Considering that the primary roles of the reticulo-rumen are nutrient digestion and absorption of SCFA, the transient changes during adaptation may also affect the time course of adaptation for more distal regions of the GIT.

\section{Adaptation of the Omasum}

The importance of the omasum for digestion and absorption in ruminants is often neglected. However, up to $10 \%$ of NDF can be digested in the omasum (Smith, 1984; Ahvenjärvi et al., 2000), and up to $15 \%$ of SCFA produced in the rumen are absorbed before they reach the duodenum, suggesting significant SCFA absorption in the omasum (Rupp et al., 1994). We observed that the omasal digesta mass for MGD steers was less than for CTRL steers, and this likely reflected lower NDF intake. The reduced omasal digesta mass we observed corresponded with results of other studies that reported lower mass in ruminants as the proportion of grain in the diet increased (Bailey, 1986). Furthermore, lower omasal digesta mass explains a reduction in omasal tissue mass after the shift to the MGD, simply because less tissue (epithelium, muscles) is needed when the amount of digesta is reduced. In line with results of the present study, others have observed lower omasal tissue mass for ruminants fed high-grain diets compared to high-forage diets (Hamada et al., 1976; Bailey, 1986; McLeod and Baldwin, 2000). However, it is not clear whether the changes observed for the omasum were due to reduced muscle mass, epithelial mass, or both. Feeding high-concentrate $\operatorname{diets}(65 \%$ of DM) to goats decreased omasal digesta $\mathrm{pH}$, increased endotoxin concentration in the omasum, and impaired barrier function of the omasal epithelium as indicated by a thinner epithelium, sloughing of the stratum corneum, and reduced expression of tight-cell junction proteins (Liu et al., 2014). It is likely that the reduction in omasal tissue mass we observed was at least partially due to reduced epithelial thickness and mass. Moreover, although a substantial reduction (13\%) in omasal tissue weight occurred within $21 \mathrm{~d}$, the omasal tissue mass decreased predominantly between d 14 and 21 after the dietary change, and the linear response indicates that the retrogressive adaptive response was not complete.

Assuming that 5 to $10 \%$ of dietary fiber is digested in the omasum, it can be predicted that the omasal digesta retention time does not exceed several hours (Ahvenjärvi et al., 2000). Because the dietary change to MGD reduced NDF intake, we could expect that the corresponding reduction in omasal digesta mass should occur immediately in response to dietary change (e.g., d 3 to 7 ) and be less pronounced thereafter (d 7 to 21). However, this was not the case in the present study. Although omasal digesta mass decreased by almost $30 \%$ in the first week after the shift to the MGD, we also observed a substantial decrease (by 17\%) between d 14 and 21. We can provide at least 2 explanations for this pattern of change. First, the increased proportion of grain in the diet may have reduced the omasal digesta $\mathrm{pH}$, as shown in goats (Liu et al., 2014), and this may have negatively affected the digestion of fiber already entrapped between omasal leaves, resulting in longer digesta retention time in the omasum. Second, at least part of the starch consumed was fermented in the omasum. Although the fermentation rate of starch $(\% / \mathrm{h})$ is higher than that of fiber (Zicarelli et al., 2011), the omasal microflora would need time to adapt to the dietary change.

Taken together, our results showed gradual but sustained reduction in the omasal digesta mass that occurred for as long as 3 wk after an abrupt shift to the MGD. The reduction in digesta mass corresponded to a reduction in omasal tissue mass that occurred predominantly after $14 \mathrm{~d}$ of exposure to the MGD. Taking into account the fact that omasal digesta and tissue mass were still decreasing between d 14 and 21 after the shift to the MGD, $21 \mathrm{~d}$ was likely insufficient for omasal adaptation.

\section{Adaptation of the Abomasum}

Few studies have evaluated the adaptation of the abomasum in cattle in response to dietary change. One study reported a substantial increase in abomasal tissue mass during the transition from the dry period to lactation (Reynolds et al., 2004). This change corresponded with DMI that was higher after parturition compared with the dry period, and that continued to increase in early lactation. The increased DMI was suggested as a partial explanation for a demand for greater abomasal tissue mass (Reynolds et al., 2004). On the other hand, Bailey (1986) found no difference in abomasal tissue mass in steers fed ad libitum high- or low-concentrate diets, and McLeod and Baldwin (2000) found lower abomasal tissue mass in sheep fed a high-concentrate diet compared with sheep fed a high-forage diet. It is 
important to note that in the study of McLeod and Baldwin (2000), energy intake was equal between the treatments (and thus DMI was higher for the sheep fed a high-concentrate diet). To partially separate the role of DMI and dietary fermentability, we kept DMI constant for all treatments in the present study. Nevertheless, increasing the proportion of grain in the diet could increase microbial protein synthesis in the rumen and the amount of microbial and total protein flowing to the abomasum, at least when feed intake is limited (Jaakkola and Huhtanen, 1993; Lascano et al., 2016). Taking into account the important role of the abomasum in protein digestion, this situation could explain the tendency we observed for a linear increase in abomasal tissue mass following the dietary shift to the MGD. Furthermore, abomasal infusions of both protein and non-structural carbohydrates affect the secretion of GIT regulatory peptides (Swanson et al., 2004; Relling and Reynolds, 2008). This, in turn, may affect abomasal tissue growth, based on the trophic effect of GIT peptides (Guilloteau et al., 2009). Future studies are needed to evaluate the regulating factors that promote adaptation of the abomasum and how nutrient supply to the abomasum alters its function.

\section{Adaptation of the Small Intestine}

Of the investigated sections of the small intestine, only duodenal tissue mass tended to increase after the dietary change to MGD. This increase occurred without an increase in duodenum length, suggesting that it was related to changes in the epithelium or muscle mass. However, assuming no change in intestinal length, 90\% of the increase in intestinal mass is accounted for by epithelial growth (McLeod and Baldwin, 2000), such as an increased villi size (Zitnan et al., 2003; Wang et al., 2009). In line with the tendency for greater duodenal mass we observed in the present study, Zitnan et al. (2003) found longer villi and greater crypt depth in the duodenum of bulls fed high-concentrate diets compared to bulls fed low-concentrate diets. We interpreted the tendency for greater duodenal mass after the shift to a MGD to be the result of epithelial growth.

Intestinal epithelial growth is driven by nutrient availability (McLeod and Baldwin, 2000; Habold et al., 2004), and this suggests that nutrient flow to the duodenum likely increased in response to the MGD. The tendency for increased duodenal mass was also supported by a tendency for linearly increased abomasal tissue mass. With moderate- to high-grain diets, the amount of starch that bypasses the reticulo-rumen increases compared with high-forage diets (Reynolds, 2006; Li et al., 2012). Furthermore, the supply of rapidly fermented carbohydrates may increase microbial protein synthesis and protein flow out of the rumen (Jaakkola and Huhtanen, 1993; Lozano et al., 2016). The fact that the duodenum is the first section of the intestine exposed to this increased nutrient flow may explain the adaptive response in this compartment of the GIT. However, the length of the duodenum accounts for only a small portion of the entire small intestine (less than $2.6 \%$ in this study) and its contribution to nutrient absorption is low. In this study, we did not observed changes in the mass or length of the jejunum, a region where substantial nutrient absorption is expected to occur.

Besides the adaptational changes in the duodenum, the results of this and other studies suggest that the ileum responds to increased dietary grain inclusion in ruminants (Wang et al., 2009; Liao et al., 2010). In contrast to the duodenum, we found that ileal mass was not affected but its length increased, indicating that ileal thickness was reduced after the shift to the MGD. When expressed as weight per unit of intestinal surface, epithelial weight was shown to be the greatest in the ileum of cattle relative to other regions of the small intestine (Kreikemeier et al., 1990). Furthermore, changes in small intestinal mass are predominantly a result of changes of epithelial mass and intestine length (McLeod and Baldwin, 2000). Therefore, a longer ileum without corresponding greater tissue mass indicates a thickening of epithelium in this section of the small intestine in response to the MGD. A linear increase for ileal length with days fed MGD was accompanied by increased LPS concentration in the ileal digesta (Plaizier et al., 2014). Greater intake of grain increases starch and simple sugar flow to the lower regions of the small intestine and colon ( $\mathrm{Li}$ et al., 2012; Metzler-Zebeli et al., 2013; Brake et al., 2014), because of limited starch assimilation in ruminants (Harmon, 2009; Brake et al., 2014). This promotes gram-negative bacteria growth, which is associated with an increase in endotoxin concentration in the GIT (Li et al., 2012; Liu et al., 2013; Metzler-Zebeli et al., 2013), in turn negatively affecting the GIT epithelial structure (Chin et al., 2006; Liu et al., 2013; Metzler-Zebeli et al., 2013). It is unclear how ileal length and risk for LPS exposure are related, but increased ileum length may be also a part of adaptational changes to increase surface area for nutrient absorption. Liao et al. (2010) found that starch hydrolysate infusion into the abomasum led to an upregulation of sodium-dependent glucose transporter 1 and facilitated glucose transporter 2 in the ileum, indicating that besides adaptation of ileum length, functional adaptation of this region of GIT in response to diet occurred. The extent to which adaptation of the ileum determines the efficiency of nutrient use in cattle fed high-grain diets requires further study. However, a 
linear increase in ileal length suggests that studies with a longer duration are needed to determine the time required for ileal adaptation.

Because functional adaptation of the small intestinal epithelium precedes structural adaptation and may be very rapid (Ferraris and Vinnakota, 1995), adaptation of brush border enzymes, if any, would be expected to occur within several days after the shift to the MGD. However, in the present study, activities of lactase in the jejunum, maltase in the duodenum, aminopeptidase $\mathrm{N}$ in the jejunum, and dipeptidylpeptidase IV in the ileum progressively increased with days on the MGD. This progressive increase indicates that adaptation of brush border enzymes in cattle is not a rapid process, also reported for pancreas secretions (Chittenden et al., 1984). The extended period required for brush border enzyme activity may be affected by the time required for preceding regions of the GIT to adapt to the dietary change, as already discussed. Duodenal infusion of nonessential amino acids in cattle decreased the flow of small $\alpha$-glycosides to the ileum, indicating more efficient starch digestion as a result of greater maltase and isomaltase activity (Brake et al., 2014). Increased grain intake stimulates microbial protein synthesis and increases the amount of amino acids entering small intestine (Merchen et al., 1986; Jaakkola and Huhtanen, 1993; Lascano et al., 2016). However, microbial adaptation is not a rapid process (Tajima et al., 2001; Fernando et al., 2010). Gradual changes in the supply of amino acids (as well as other nutrients) entering small intestine after dietary change may lead to gradual changes in brush border enzymes activity. Furthermore, brush border enzyme activity increases would be initiated from the base of the villi, and the life span of enterocytes, depending on the section of the small intestine, varies from 2 to several days (ShiraziBeechey et al., 1991; Fan et al., 2001). The division, maturation, and migration of enterocytes would present a lag for adaptation of brush border enzyme activity in response to dietary change.

Although the results of this study do not answer whether the total GIT activity of investigated brush border enzymes was affected by the MGD, the activity of lactase, maltase and aminopeptidase $\mathrm{N}$ did increase in the proximal section of the small intestine after the shift to the MGD. Kreikemeier et al. (1990) found that greater feed intake and the associated increased energy intake resulted in greater small intestinal brush border disaccharidase activity, but they detected no differences between animals fed diets high in forage or high in concentrate. In the current study, the MGD was associated with greater energy intake than the CTRL diet, providing additional evidence that brush border enzyme activity in cattle is affected by energy intake.
On the other hand, Zitnan et al. (2003) did not find differences in maltase or lactase activity in the duodenum, jejunum, and ileum in bulls fed a high-concentrate diet compared with bulls fed a low-concentrate diet.

\section{CONCLUSIONS}

Our results indicate that adaptation to diets with a moderate grain content involves a decrease in omasal digesta and tissue mass and an increase in abomasal and duodenal tissue mass, ileal length, and the activity of some brush border enzymes. Furthermore, most of the adaptive responses progressed throughout the study, suggesting that 3 weeks is not sufficient to complete the adaptive response.

\section{ACKNOWLEDGMENTS}

Financial support was provided by the Natural Sciences and Engineering Research Council of Canada Discovery Grant (Penner) and the Ministry of Science and Higher Education of Poland (BM-4234/KŻZiP/2014).

\section{REFERENCES}

Ahvenjärvi, S., A. Vanhatalo, P. Huhtanen, and T. Varvikko. 2000. Determination of reticulo-rumen and whole-stomach digestion in lactating cows by omasal canal or duodenal sampling. Br. J. Nutr. $83: 67-77$.

Amat, S., J. J. McKinnon, G. B. Penner, and S. Hendrick. 2014. Effects of dietary sulfur concentration and forage-to-concentrate ratio on ruminal fermentation, sulfur metabolism, and short-chain fatty acid absorption in beef heifers. J. Anim. Sci. 92:712-723.

Aschenbach, J. R., G. B. Penner, F. Stumpff, and G. Gäbel. 2011. Ruminant nutrition symposium: Role of fermentation acid absorption in the regulation of ruminal pH. J. Anim. Sci. 89:1092-1107.

Bailey, C. B. 1986. Growth of digestive organs and their contents in Holstein steers: Relation to body weight and diet. Can. J. Anim. Sci. 66:653-661.

Bannink, A., J. France, S. Lopez, W. J. J. Gerrits, E. Kebreab, S. Tammingad, and J. Dijkstra. 2008. Modelling the implications of feeding strategy on rumen fermentation and functioning of the rumen wall. Anim. Feed Sci. Technol. 143:3-26.

Brake, D. W., E. C. Titgemeyer, and D. E. Anderson. 2014. Duodenal supply of glutamate and casein both improve intestinal starch digestion in cattle, but by apparently different mechanisms. J. Anim. Sci. 92:4057-4067.

Calsamiglia, S., A. Ferret, and M. Devant. 2002. Effects of pH and $\mathrm{pH}$ fluctuations on microbial fermentation and nutrient flow from a dual-flow continuous culture system. J. Dairy Sci. 85:574-579.

Chibisa, G. E., K. A. Beauchemin, and G. B. Penner. 2016. Relative contribution of ruminal buffering systems to $\mathrm{pH}$ regulation in feedlot cattle fed either low- or high-forage diets. Animal 10:1164-1172.

Chin, A. C., A. N. Flynn, J. P. Fedwick, and A. G. Buret. 2006. The role of caspase-3 703 in lipopolysaccharide-mediated disruption of intestinal epithelial tight 704 junctions. Can. J. Physiol. Pharmacol. 84:1043-1050.

Chittenden, L. W., D. D. Johnson, G. E. Mitchell, and R. E. Tucker 1984. Ovine pancreatic amylase response to form of carbohydrate. Nutr. Rep. Int. 29:1051-1060.

Colucci, P. E., G. K. Macleod, W. L. Grovum, I. McMillan, and D. J. Barney. 1990. Digesta kinetics in sheep and cattle fed diets with 
different forage to concentrate ratios at high and low intakes. J. Dairy Sci. 73:2143-2156.

Dahlqvist, A. 1984. Assay of intestinal disaccharidases. Scand. J. Clin. Lab. Invest. 44:169-172.

DeVries, T. J., T. Schwaiger, K. A. Beauchemin, and G. B. Penner 2014. The duration of time that beef cattle are fed a high-grain diet affects feed sorting behavior both before and after acute ruminal acidosis. J. Anim. Sci. 92:1728-1737.

Dieho, K., A. Bannink, I. A. L. Geurts, J. T. Schonewille, G. Gort, and J. Dijkstra. 2016. Morphological adaptation of rumen papillae during the dry period and early lactation as affected by rate of increase of concentrate allowance. J. Dairy Sci. 99:2339-2352.

Dirksen, G., H. Liebich, and K. Mayer. 1985. Adaptive changes of the ruminal mucosa and functional and clinical significance. Bovine Pract. 20:116-120.

Etschmann, B., A. Suplie, and H. Martens. 2009. Change of ruminal sodium transport in sheep during dietary adaptation. Arch. Anim. Nutr. 63:26-38.

Fan, M. Z., B. Stoll, R. Jiang, and D. G. Burrin. 2001. Enterocyte digestive enzyme activity along the crypt-villus and longitudinal axes in the neonatal pig small intestine. J. Anim. Sci. 79:371-381.

Fernando, S. C., H. T. Purvis 2nd, F. Z. Najar, L. O. Sukharnikov, C R. Krehbiel, T. G. Nagaraja, B. A. Roe, and U. Desilva. 2010. Rumen microbial population dynamics during adaptation to a highgrain diet. Appl. Environ. Microbiol. 76:7482-7490.

Ferraris, R. P., and R. R. Vinnakota. 1995. The time course of adaptation of intestinal nutrient uptake in mice is independent of age. J. Nutr. 125:2172-2182.

Goodlad, R. A. 1981. Some effects of diet on the mitotic index and the cell cycle of the ruminal epithelium of sheep. Q. J. Exp. Physiol. 66:487-499.

Górka, P., Z. M. Kowalski, P. Pietrzak, A. Kotunia, W. Jagusiak, and R. Zabielski. 2011. Is rumen development in newborn calves affected by different liquid feeds and small intestine development? J. Dairy Sci. 94:3002-3013.

Guilloteau, P., R. Zabielski, and J. W. Blum. 2009. Gastrointestinal tract and digestion in the young ruminant: Ontogenesis, adaptations, consequences and manipulations. J. Physiol. Pharmacol. 60(Suppl. 3):37-46.

Habold, C., C. Chevalier, S. Dunel-Erb, C. Foltzer-Jourdainne, Y. Le Maho, and J. H. Lignot. 2004. Effects of fasting and refeeding on jejunal morphology and cellular activity in rats in relation to depletion of body stores. Scand. J. Gastroenterol. 39:531-539.

Hamada, T., S. Maeda, and K. Kameoka. 1976. Factors influencing growth of rumen, liver, and other organs in kids weaned from milk replacers to solid foods. J. Dairy Sci. 59:1110-1118.

Harmon, D. L. 2009. Understanding starch utilization in the small intestine of cattle. Asian-australas. J. Anim. Sci. 22:915-922.

Harrison, H. N., R. G. Warner, E. G. Sander, and J. K. Loosil. 1960. Changes in the tissue and volume of the stomachs of calves following removal of dry feed or consumption of inert bulk. J. Dairy Sci. 43:1301-1312.

Hartree, E. F. 1972. Determination of protein: A modification of the Lowry method that gives a linear photometric response. Anal. Biochem. 48:422-427.

Jaakkola, S., and P. Huhtanen. 1993. The effects of forage preservation method and proportion of concentrate on nitrogen digestion and rumen fermentation in cattle. Grass Forage Sci. 48:146-154.

Krehbiel, C. R., R. A. Britton, D. L. Harmon, T. J. Wester, and R. A Stock. 1995. The effects of ruminal acidosis on volatile fatty acid absorption and plasma activities of pancreatic enzymes in lambs. J. Anim. Sci. 73:3111-3121.

Kreikemeier, K. K., D. L. Harmon, J. P. Peters, K. L. Gross, C. K. Armendark, and C. R. Krehbiel. 1990. Influence of dietary forage and feed intake on carbohydrase activities and small intestinal morphology of calves. J. Anim. Sci. 68:2916-2929.

Lascano, G. J., L. E. Koch, and A. J. Heinrichs. 2016. Precision-feeding dairy heifers a high rumen-degradable protein diet with different proportions of dietary fiber and forage-to-concentrate ratios. J. Dairy Sci. 99:7175-7190.
Li, H. Z., T. Ran, Z. X. He, Q. X. Yan, S. X. Tang, and Z. L. Tan 2016. Postnatal developmental changes of the small intestinal villus height, crypt depth and hexose transporter mRNA expression in supplemental feeding and grazing goats. Small Rumin. Res. 141:106-112.

Li, S., E. Khafipour, D. O. Krause, A. Kroeker, J. C. RodriguezLecompte, G. N. Gozho, and J. C. Plaizier. 2012. Effects of subacute ruminal acidosis challenges on fermentation and endotoxins in the rumen and hindgut of dairy cows. J. Dairy Sci. 95:294-303.

Liao, S. F., D. L. Harmon, E. S. Vanzant, K. R. McLeod, J. A. Boling, and J. C. Matthews. 2010. The small intestinal epithelia of beef steers differentially express sugar transporters messenger ribonucleic acid in response to abomasal versus ruminal infusion of starch hydrolysate. J. Anim. Sci. 88:306-314.

Liu, J. H., T. T. Xu, Y. J. Liu, W. Y. Zhu, and S. Y. Mao. 2013 A high-grain diet causes massive disruption of ruminal epithelial tight junctions in goats. Am. J. Physiol. Regul. Integr. Comp. Physiol. 305:R232-R241.

Liu, J. H., T. T. Xu, W. Y. Zhu, and S. Y. Mao. 2014. A high-grain diet alters the omasal epithelial structure and expression of tight junction proteins in a goat model. Vet. J. 201:95-100.

Maekawa, M., K. A. Beauchemin, and D. A. Christensen. 2002. Effect of concentrate level and feeding management on chewing activities, saliva production, and ruminal $\mathrm{pH}$ of lactating dairy cows. J. Dairy Sci. 85:1165-1175.

Malhi, M., H. Gui, L. Yao, J. R. Aschenbach, G. Gabel, and Z. Shen 2013. Increased papillae growth and enhanced short-chain fatty acid absorption in the rumen of goats are associated with transient increases in cyclin D1 expression after ruminal butyrate infusion. J. Dairy Sci. 96:7603-7616.

Maroux, S., D. Louvard, and J. Baratti. 1973. The aminopeptidases from hog intestinal brush border. Biochim. Biophys. Acta 321:282295.

McLeod, K. R., and R. L. Baldwin., 6th2000. Effects of diet forage:concentrate ratio and metabolizable energy intake on visceral organ growth and in vitro oxidative capacity of gut tissues in sheep. J. Anim. Sci. 78:760-770.

Merchen, N. R., J. L. Firkins, and L. L. Berger. 1986. Effect of intake and forage level on ruminal turnover rates, bacterial protein synthesis and duodenal amino acid flows in sheep. J. Anim. Sci. 62:216-225.

Metzler-Zebeli, B. U., M. Hollmann, S. Sabitzer, L. Podstatzky-Lichtenstein, D. Klein, and Q. Zebeli. 2013. Epithelial response to high-grain diets involves alteration in nutrient transporters and $\mathrm{Na}+/ \mathrm{K}+-\mathrm{ATPase}$ mRNA expression in rumen and colon of goats. J. Anim. Sci. 91:4256-4266.

Nagaraja, T. G.. and E. C. Titgemeyer. 2007. Ruminal acidosis in beef cattle: The current microbiological and nutritional outlook. J. Dairy Sci. 90(E. Suppl.):E17-E38.

Nagatsu, T., M. Hino, H. Fuyamada, H. Hayakawa, T. Sakakibara, Y Nakagawa, and T. Takemoto. 1976. New chromogenic substrates for X-propyl dipeptidyl-aminopeptidase. Anal. Biochem. 74:466476.

NRC. 2000. Nutrient Requirements of Beef Cattle: Update. 7th ed. Natl. Acad. Press, Washington, DC.

Plaizier, J. C., D. O. Krause, G. N. Gozho, and B. W. McBride. 2008 Subacute ruminal acidosis in dairy cows: The physiological causes, incidence and consequences. Vet. J. 176:21-31.

Plaizier, J. C., S. Li, M. Le Sciellour, B. L. Schurmann, P. Górka and G. B. Penner. 2014. Effects of duration of moderate increases in grain feeding on endotoxins in the digestive tract and acute phase proteins in peripheral blood of yearling calves. J. Dairy Sci. 97:7076-7084

Relling, A. E., and C. K. Reynolds. 2008. Abomasal infusion of casein, starch and soybean oil differentially affect plasma concentrations of gut peptides and feed intake in lactating dairy cows. Domest. Anim. Endocrinol. 35:35-45.

Reynolds, C. K. 2006. Production and metabolic effects of site of starch digestion in dairy cattle. Anim. Feed Sci. Technol. 130:78-94.

Reynolds, C. K., B. Durst, B. Lupoli, D. J. Humphries, and D. E. Beever. 2004. Visceral tissue mass and rumen volume in dairy 
cows during the transition from late gestation to early lactation. J. Dairy Sci. 87:961-971.

Rupp, G. P., K. K. Kreikemeier, L. J. Perino, and G. S. Ross. 1994. Measurement of volatile fatty acid disappearance and fluid flux across the abomasum of cattle, using an improved omasal cannulation technique. Am. J. Vet. Res. 55:522-529.

Schurmann, B. L., M. E. Walpole, P. Gorka, J. C. H. Ching, M. E. Loewen, and G. B. Penner. 2014. Short-term adaptation of the ruminal epithelium involves abrupt changes in sodium and shortchain fatty acid transport. Am. J. Physiol. Regul. Integr. Comp. Physiol. 307:R802-R816.

Schwaiger, T., K. A. Beauchemin, and G. B. Penner. 2013. The duration of time that beef cattle are fed a high-grain diet affects the recovery from a bout of ruminal acidosis: Dry matter intake and ruminal fermentation. J. Anim. Sci. 91:5729-5742.

Shirazi-Beechey, S. P., M. W. Smith, Y. Wang, and P. S. James. 1991. Postnatal development of lamb intestinal digestive enzymes is not regulated by diet. J. Physiol. 437:691-698.

Smith, R. H. 1984. Microbial activity in the omasum. Proc. Nutr. Soc. 43:63-68.

Steele, M. A., J. Croom, M. Kahler, O. AlZahal, S. E. Hook, K. Plaizier, and B. W. McBride. 2011. Bovine rumen epithelium undergoes rapid structural adaptations during grain-induced subacute ruminal acidosis. Am. J. Physiol. Regul. Integr. Comp. Physiol. 300:R1515-R1523.

Stobo, I. J. F., J. H. B. Roy, and H. J. Gaston. 1966. Rumen development in the calf: 1 . The effect of diets containing different proportions of concentrates to hay on rumen development. Br. J. Nutr. 20:171-188.

Swanson, K. C., J. A. Benson, J. C. Matthews, and D. L. Harmon. 2004. Pancreatic exocrine secretion and plasma concentration of some gastrointestinal hormones in response to abomasal infusion of starch hydrolyzate and/or casein. J. Anim. Sci. 82:1781-1787.

Tajima, K., R. I. Aminov, T. Nagamine, H. Matsui, M. Nakamura, and Y. Benno. 2001. Diet-dependent shifts in the bacterial population of the rumen revealed with real-time PCR. Appl. Environ. Microbiol. $67: 2766-2774$.

Walpole, M. E., B. L. Schurmann, P. Górka, G. B. Penner, M. E. Loewen, and T. Mutsvangwa. 2015. Serosal-to-mucosal urea flux across the isolated ruminal epithelium is mediated via urea transporter-B and aquaporins when Holstein calves are abruptly changed to a moderately fermentable diet. J. Dairy Sci. 98:1204-1213.

Wang, Y. H., M. Xu, F. N. Wang, Z. P. Yu, J. H. Yao, L. S. Zan, and F. X. Yang. 2009. Effect of dietary starch on rumen and small intestine morphlogy and digesta $\mathrm{pH}$ in goats. Livest. Sci. 122:48-52.

Wilson, D. J., T. Mutsvangwa, and G. B. Penner. 2012. Supplemental butyrate does not enhance the absorptive or barrier functions of the isolated ovine ruminal epithelia. J. Anim. Sci. 90:3153-3161.

Zebeli, Q., J. Dijkstra, M. Tafaj, H. Steingass, B. N. Ametaj, and W. Drochner. 2008. Modeling the adequacy of dietary fiber in dairy cows based on the responses of ruminal $\mathrm{pH}$ and milk fat production to composition of the diet. J. Dairy Sci. 91:2046-2066.

Zicarelli, F., S. Calabro, M. I. Cutrignelli, F. Infascelli, R. Tudisco, F. Bovera, and V. Piccolo. 2011. In vitro fermentation characteristics of diets with different forage/concentrate ratios: Comparison of rumen and faecal inocula. J. Sci. Food Agric. 91:1213-1221.

Zitnan, R., S. Kuhla, K. Nurnberg, U. Schonhusen, Z. Ceresnakova, A. Sommer, M. Baran, G. Greserova, and J. Voigt. 2003. Influence of the diet on the morphology of ruminal and intestinal mucosa and on intestinal carbohydrase levels in cattle. Vet. Med.-Czech. $48: 177-182$. 